\title{
A avaliação da educação básica no Brasil: dimensão normativa, pedagógica e educativa
}

Dirce Nei Teixeira de Freitas

Campinas, SP: Autores Associados, 2007, 224 p.

Escrito originalmente como tese de doutoramento da autora, o texto aborda o complexo tema da avaliação da perspectiva de sua utilização no campo da política pública para a educação básica, no Brasil, no período 1988-2002.

A atualidade e importância acadêmica dessa abordagem são inegáveis. A produçáo sobre a avaliação em larga escala no país mostra-se não só escassa, mas polarizada entre a crítica da sua lógica economicista e a afirmação da necessidade de aprimorá-la e bem utilizá-la como ferramenta de regulaçâo do Estado. Neste segundo polo, as abordagens descritivo-analíticas são comuns, enquanto no primeiro estão as análises voltadas à crítica ideológica e política das iniciativas estatais.

Sem cair nessa polarizaçáo, a autora oferece elementos para o leitor pensar o Estado-avaliador brasileiro como síntese do Estado-regulador e do Estado-educador. Analisa como se deu a emergência e a afirmação da avaliaçáo em larga escala na regulação da educação básica no país e como ela operou enquanto ação educativa estatal. Orienta os seus procedimentos no sentido de conhecer o processo, sua razáo de ser, sua força normativa, natureza pedagógica e suas implicaçôes educativas.

No primeiro capítulo, por meio de uma retrospectiva histórica institucional, a autora mostra como, no caso brasileiro, a avaliaçáo veio a se tornar uma importante ferramenta de política pública no campo da educação básica, explicitando as vias 
utilizadas, as articulaçóes estabelecidas, os fatores impulsionadores, as "razóes de Estado", bem como a posição dos agentes e interlocutores estratégicos na relação entre Estado, sociedade e educação.

A autora observa que somente ao término dos anos 1980 o interesse estatal pela avaliação culminaria numa prática mais sistemática e de larga escala que, coerente com o projeto de modernização da administração estatal, se distancia do debate acadêmico sobre educação e democracia desse período. No contexto da crescente internacionalizaçáo do trato das questôes educacionais, ela seria um "dispositivo" útil na mediação entre o local e o global.

A retrospectiva termina chamando a atençáo para peculiaridades do Estado brasileiro do período 1930-1988, que seriam importantes para a compreensão da ação reguladora e educadora do Estado. Afirma a autora que essa ação se configura na inexistência de um projeto hegemônico (econômico e político), o que enseja reformismo com uma agenda restritiva para a área social. No caso da educaçáo básica, a estratégia de descentralização conjugada com o controle centralizado passa a ter na avaliação externa e em larga escala importante ferramenta.

No segundo capítulo, a autora trata do processo de montagem e instituiçáo do complexo de regulação "medida-avaliação-informação" da educação básica brasileira, no período 1988-2002, cujo intuito seria vencer a falta de equidade, qualidade e eficiência na educação brasileira. Nessa direção, por meio de um competente tratamento descritivo e analítico-crítico do processo normativo legal, mostra como se deu a afirmação da avaliação como ferramenta da nova regulação educacional no país.

O Estado brasileiro, segundo a autora, cuidou não apenas de estabelecer normas jurídico-legais e político-administrativas com vistas às mudanças pretendidas, mas agiu operacionalmente por meio da avaliação em larga escala e da concentraçáo da informação educacional. Com isso, ocorreu

[...] acentuada subordinação do CNE ao MEC, com o que a ação normativa desse órgão reforçou a regulação central [...] Em contrapartida, o INEP concentrou poder decisório e operacional, tornando-se o órgão "mensurador-avaliador" da educação no país. Esses caminhos ensejaram uma ampliação extraordinária do aparato de regulação do Estado central. (p.120)

Para evidenciar sua constatação, Freitas apresenta (p.128-132) dois quadros nos quais elenca as normas, as açóes e os eventos realizados como fórum de discussão e mobilização das ações governamentais para a educação básica no Brasil. 
No entanto, a montagem do aparato para medir-avaliar-informar, sua expansão e contínua calibração têm, segundo a autora, relativo êxito na regulação da educação básica, pois "[...] a realidade escolar insiste em descortinar os estreitos limites dentro dos quais tal aparato opera, bem como as análises reducionistas que propicia” (p. 98).

Para Freitas, o desafio passa pelo estabelecimento de políticas públicas que contemplem a "escola real", que compartilha cotidianamente com alunos e professores o "mal-estar social" que vigora numa sociedade e Estado minimamente comprometidos com o bem-estar social.

No terceiro capítulo, a autora passa para o seu propósito final: o funcionamento do complexo de regulaçáo educacional pelo qual o Estado-educador se manifestou e operou como Estado-avaliador. Tendo passado em "revista" a dimensão normativa do Estado brasileiro no que diz respeito à avaliação da educação básica, a autora caminhou para evidenciar como se deu a tessitura das dimensóes pedagógica e educativa da ação estatal. Para isso busca os princípios, os meios e as formas de atuação do Estado que caracterizam a dimensão pedagógica e configuram os aspectos formativos do agir estatal.

Apoiando-se na noção "Estado-educador" de Gramsci, as análises da autora podem ser questionadas por algum marxiano de "plantão" que assevera ser o "[...] Estado que necessita [...] uma educação severa” (Marx, 1975, p.56). Todavia, tal discussão não cabe no momento, importa lembrar que, "[...] tendo natureza histórica, o Estado-educador e o Estado-avaliador emergem do contexto histórico que define e emoldura o próprio Estado e a sua relação com a sociedade" (p. 134).

De fato, a reestruturação da organizaçáo e gestão do sistema educacional na América Latina ocorrida nos anos 1990 trouxe, em graus diferenciados, a mudança do caráter regulador do Estado com a crescente importância das redes de informação e comunicação, para facilitar e fortalecer a capacidade de gestão nos diferentes níveis do sistema.

No Brasil, o Estado-avaliador resultaria do empenho do Estado-educador em difundir

[...] determinados conhecimentos, valores e visóes de mundo, signos e símbolos da cultura hegemônica, tendo sido ela condicionada por uma "agenda globalmente estruturada para a educação". Isso se deu especialmente por meio de fixação de parâmetros e diretrizes curriculares nacionais, de certo controle editorial, de um "novo" modelo de gestão e de mecanismos e de práticas de controle e de avaliação. (p.112) 
No avanço do Estado-avaliador, a avaliação "[...] passou a ser uma das mediações imprescindíveis e valorizadas num planejamento cuja conformação tem-se dado [...] na/pela relação entre âmbitos internacional, nacional e local [...]"(p. 140). Assim, o Estado-avaliador se firmou e ascendeu "[...] pelo re-arranjo institucional e administrativo estratégico para que o projeto de modernizaçáo conservadora da sociedade brasileira lograsse ser hegemônica no País" (p. 148).

Ninguém melhor do que a própria autora poderia sintetizar a conclusão de sua pesquisa, que, aliás, deve figurar como obrigatória na bibliografia sobre avaliaçáo da educação básica: "reconhece-se a legitimidade e a indispensabilidade do Estado-educador para qualificar a educaçáo básica brasileira, como, também, a possibilidade de que o Estado-avaliador se constitua em uma mediação profícua para tanto" (p. 151). Ou seja, a rigor, a autora conclui pela preservação da atuação estatal como o agente habilitado para gerenciar os destinos da educação básica, contudo, aponta algumas condiçóes necessárias para que se impeça o desvirtuamento que ocorre no interior do Estado, como, por exemplo, "[...] a atuação efetiva de um Estado provedor do direito à educação de todos, sem exceções e sem soluçóes precárias [...]”(p. 151).

Finalmente mister se faz deixar claro que apresentamos apenas um "trailer" do riquíssimo estudo realizado pela autora à guisa de um convite para que o leitor, especialmente aqueles interessados na avaliação da educação básica, confira, na íntegra, a contribuição da autora. Contudo, alertamos: o texto não contém "receitas" de alcance limitado e até duvidoso, trata-se de uma reflexão teórica densa recomendada como fonte de consulta. Melhor dizendo, sem querer separar os aspectos teóricos e as aplicações práticas, o estudo de Freitas não se configura "um manual de avaliação", isto é, um livro no qual os educadores "aprenderiam" a avaliar seus alunos.

O que os formadores e os "formadores de formadores" nele encontrarão são os fundamentos da avaliação em larga escala e sua utilização como estratégia de governo, com o fito de reger e controlar a educação básica no Brasil. Assim, poderão esclarecer a seus alunos, e futuros educadores, o que representa no cotidiano da escola e na avaliação de sala de aula o Sistema Nacional de Avaliação da Educação Básica (Saeb) e o Exame Nacional do Ensino Médio (Enem) e outros.

Em suma, náo se trata de uma leitura fácil, nem poderia, visto ser resultado de uma tese de doutoramento, mas certamente quem se dispuser a ler, mesmo que por diletantismo, se surpreenderá com a excelente qualidade do texto. A autora, como ocorre com os grandes escritores, leva a sério o seu assunto.

Ainda há, nesse livro, um último aspecto que deve ser ressaltado, a autora parece não temer o debate. Com ousadia e contra uma tendência quase hegemônica no 
interior da intelectualidade brasileira, Freitas afirma e argumenta a improcedência da tese de se atribuir a iniciativa do Estado brasileiro de introduzir a regulamentação avaliativa na educaçáo básica desde a imposiçáo de organismos internacionais, embora náo seja ingênua a ponto de negar a nítida influência deles em tal iniciativa. A coragem da autora vai além ao afirmar que é igualmente improcedente a tese de se atribuir ao Governo FHC (1995-2002) a exclusiva responsabilidade pela criação das condiçóes potencializadoras da força normativa do Estado na educação básica. Enfim, entre o risco do "adesismo" e o risco de expor teoricamente, preferiu o último. A nosso ver, uma boa escolha, pois assim seu trabalho será um estímulo ao debate e à pesquisa na área.

Além do excelente nível de produção acadêmica, o texto é um exemplo de trabalho metodologicamente fecundo e rigoroso, e, ao mesmo tempo, historicamente rico e desafiador, pois aponta possibilidades para novas pesquisas.

Nilce Aparecida da Silva Freitas Fedatto

Professora Doutora do Programa de Pós-Graduação em Educação da Faculdade de Educação da Universidade Federal de Grande Dourados/MS nfedatto@globo.com 